\title{
Hydrogenolysis of biomass-derived sorbitol to glycols and glycerol over Ni-MgO catalysts
}

\author{
Xinguo Chen ${ }^{\mathrm{a}, \mathrm{b}}$, Xicheng Wang ${ }^{\mathrm{a}}$, Shengxi Yao ${ }^{\mathrm{a}}$, Xindong $\mathrm{Mu}^{\mathrm{a}, *}$ \\ a Key Laboratory of Biobased Materials, Chinese Academy of Sciences, Qingdao 266101, PR China \\ ${ }^{\mathrm{b}}$ University of Chinese Academy of Sciences, Beijing 100049, PR China
}

\section{A R T I C L E I N F O}

Article history:

Received 14 March 2013

Received in revised form 10 May 2013

Accepted 15 May 2013

Available online 21 May 2013

\section{Keywords:}

Sorbitol

Hydrogenolysis

Glycols

$\mathrm{Ni}-\mathrm{MgO}$

Basic carrier

\begin{abstract}
A B S T R A C T
$\mathrm{Ni}-\mathrm{MgO}$ catalysts with varying $\mathrm{Ni} / \mathrm{Mg}$ ratios were prepared by co-precipitation and tested in sorbitol hydrogenolysis. At $473 \mathrm{~K}$ and $4 \mathrm{MPa} \mathrm{H}_{2}$, the best catalyst with $\mathrm{Ni} / \mathrm{Mg}$ ratio of 3:7 exhibited $67.8 \%$ conversion and $80.8 \%$ total selectivity of ethylene glycol, 1,2-propylene glycol and glycerol. These catalysts were characterized by $\mathrm{XRD}, \mathrm{CO}_{2}$-TPD and $\mathrm{H}_{2}$ chemisorption, revealing that the activity depended strongly on the basicity and Ni surface area. The reaction conditions were optimized, which were relatively mild for this chemoselective conversion.
\end{abstract}

(c) 2013 Elsevier B.V. All rights reserved.

\section{Introduction}

Glycerol and C2-C3 glycols containing ethylene glycol (EG) and propylene glycol (PG) are important commodity chemicals widely used in the manufacture of polyesters resins, surfactants, pharmaceuticals and functional fluids. Sugars and sugar alcohols, which can be derived largely from the renewable lignocellulosic biomass instead of fossil resources, are considered to be potential feedstocks for the production of lower glycols through hydrogenolysis because of their rich oxygen-containing functional groups [1]. Previously, the catalytic hydrogenolysis of sorbitol and other polyols was usually conducted using a metal catalyst and a basic promoter, and those promoters like $\mathrm{NaOH}$ and $\mathrm{Ca}(\mathrm{OH})_{2}$ have proved a positive influence on the $\mathrm{C}-\mathrm{C}$ scission where a widely accepted mechanism was the retro-aldol condensation [2-6]. However, such problems as accelerated degradation and glycol products separation would occur when the alkali was dissolved in the reaction solution. Without alkalis, $\mathrm{MgO}$ supported $\mathrm{Cu}$, Co and Pt catalysts showed bifunctional effects and excellent performances in the aqueous-phase hydrogenolysis of glycerol to glycols [7-9], which should be also efficient for sorbitol hydrogenolysis. Considering the high cost of noble metal catalysts, some non-noble metal catalysts with excellent $\mathrm{C}-\mathrm{C}$ bond breaking ability, like $\mathrm{Ni}$, have attracted great attention in polyols hydrogenolysis $[5,10,11]$.

\footnotetext{
* Corresponding author at: Key Laboratory of Biobased Materials, Qingdao Institute of Bioenergy and Bioprocess Technology, Chinese Academy of Sciences, Qingdao 266101, PR China. Tel.: + 86532 80662723; fax: + 8653280662724

E-mail address: muxd@qibebt.ac.cn (X. Mu).
}

Herein, the bifunctional $\mathrm{Ni}-\mathrm{MgO}$ catalysts were prepared by coprecipitation and used for sorbitol hydrogenolysis under mild conditions and without alkaline additives. The catalysts were characterized to study the relationship between the structure and their catalytic performance. We also discussed the effects of temperature, $\mathrm{H}_{2}$ pressure and reaction time.

\section{Experiment}

\subsection{Catalyst preparation and characterization}

A series of $\mathrm{Ni}-\mathrm{MgO}$ catalysts with varying $\mathrm{Ni} / \mathrm{Mg}$ molar ratios were prepared by co-precipitation [12,13]. A mixed solution (1 M total metal) of $\mathrm{Ni}\left(\mathrm{NO}_{3}\right)_{2} \cdot 6 \mathrm{H}_{2} \mathrm{O}$ and $\mathrm{Mg}\left(\mathrm{NO}_{3}\right)_{2} \cdot 6 \mathrm{H}_{2} \mathrm{O}$ was deposited by a $\mathrm{Na}_{2} \mathrm{CO}_{3}$ solution $(1.2 \mathrm{M})$ at an adding rate of $1 \mathrm{~mL} / \mathrm{min}$ at room temperature (RT). After aged overnight, isolated and washed by vacuum filtration until $\mathrm{pH}<8$, the precipitates were dried at $383 \mathrm{~K}$ for $12 \mathrm{~h}$ and calcined at $773 \mathrm{~K}$ for $3 \mathrm{~h}$ in static air, followed by reduction with pure

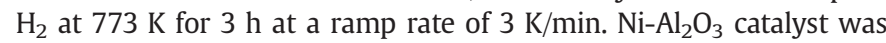
also prepared by the same procedures but with reduction temperature of $1073 \mathrm{~K}$. The NiOx sample was obtained by co-precipitation and using only $\mathrm{Ni}\left(\mathrm{NO}_{3}\right)_{2} \cdot 6 \mathrm{H}_{2} \mathrm{O}$ as precursor. All the catalysts were identified as $\mathrm{Ni}-\mathrm{Mg}(\mathrm{x}: \mathrm{y})$ or $\mathrm{Ni}-\mathrm{Al}(\mathrm{x}: \mathrm{y})$, where $\mathrm{x}: \mathrm{y}$ referred to the atomic ratio. The catalysts were characterized by ICP-AES, $\mathrm{N}_{2}$-TPD, $\mathrm{CO}_{2}$-TPD, XRD, $\mathrm{H}_{2}$-TPR and $\mathrm{H}_{2}$ chemisorption to study their physico-chemical properties and the technical details were provided in the Supporting Information (SI). 


\subsection{Catalytic test and product analysis}

Sorbitol hydrogenolysis was carried out in a batch system with a $100 \mathrm{~mL} 316 \mathrm{~L}$ stainless steel autoclave reactor. After $50 \mathrm{~mL}$ aqueous solution of $20 \%$ sorbitol and $0.5 \mathrm{~g}$ catalyst were loaded, the reactor was purged with hydrogen for four times, aerated to the desired pressure and then heated to the defined temperature for a given period at $600 \mathrm{rpm}$ stirring speed. All the experiments were carried out in triplicate. After reaction, the unconsumed sorbitol and products were quantified by both gas chromatography (GC) and ion chromatography (IC). The byproducts were analyzed by GC coupled with a mass spectrometer (MS), and the total carbon balance (TC) was also measured. The analytical methods were shown in the SI [13].

\section{Results and discussion}

\subsection{Chemical and physical properties of catalysts}

Table 1 summarized the physico-chemical properties of Ni-MgO catalysts with Ni/Mg molar ratio ranging from 1/9 to 5/5. A high surface area accompanied with a strong basicity was obtained for $\mathrm{MgO}$ sample. As Ni was introduced and increased, both the BET surface areas and the basicities of catalysts continuously decreased. The actual content of Ni was very close to the theoretical loading, which increased with the increasing $\mathrm{Ni} / \mathrm{Mg}$ ratio. Based on $\mathrm{H}_{2}$-TPR results, only a small fraction of nickel oxides could be reduced at the temperature below $700 \mathrm{~K}$ for $\mathrm{Ni}-\mathrm{MgO}$ catalysts, while the unsupported $\mathrm{NiOx}$ sample could be completely reduced at $700 \mathrm{~K}$. The Ni oxides loaded on $\mathrm{MgO}$ were more difficult to reduce than the unsupported $\mathrm{NiOx}$ and the reduction temperature rose with the increase of $\mathrm{Ni} / \mathrm{Mg}$ ratio (Fig. S1 in the SI). When the $\mathrm{Ni} / \mathrm{Mg}$ ratio increased from $1 / 9$ to $3 / 7$, the Ni surface area reached a maximum of $6.2 \mathrm{~m}^{2} / \mathrm{g}$, and subsequently dropped as the ratio continuously increased. This decrease could be attributed to the decline in catalyst reducibility and the aggregation of Ni particles [12]. As identified in Fig. 1, the diffraction lines at $44.5^{\circ}, 51.8^{\circ}$ and $76.4^{\circ}$ for $2 \theta$ were attributed to the $\mathrm{Ni}(111), \mathrm{Ni}(200)$ and $\mathrm{Ni}(220)$ crystal planes (JCPDS No. 87-0712), which showed stronger intensity as $\mathrm{Ni}$ content increased. On the other hand, the $\mathrm{MgO}$ characteristic diffraction peaks at $36.9^{\circ}, 42.9^{\circ}, 62.3^{\circ}, 74.7^{\circ}$ and $78.6^{\circ}$ for $2 \theta$ (JCPDS No. 77-2179) became weaker when Ni was introduced. The angles of $\mathrm{MgNiO}_{2}$ characteristic diffraction peaks (JCPDS No. 24-0712) were a little higher than those of MgO and $\mathrm{NiO}$ (JCPDS No. 89-7130), and a gradual shift of peaks at about $37^{\circ}, 43^{\circ}$ and $62^{\circ}$ for $2 \theta$ to the higher diffraction angles was observed after increasing partial substitution of $\mathrm{Mg}$ with $\mathrm{Ni}[14,15]$. The phenomenon indicated that the amount of $\mathrm{MgNiO}_{2}$ solid solution increased, which brought about higher reduction temperature and poorer reducibility in Ni-MgO catalysts with the increasing Ni content $[12,16]$. Ni nanoparticles grew slowly as Ni content increased. The degree of reduction was rapidly

Table 1

Characterization results of $\mathrm{Ni}-\mathrm{MgO}$ catalysts.

\begin{tabular}{|c|c|c|c|c|c|c|c|}
\hline \multirow[t]{2}{*}{ Catalyst } & \multirow{2}{*}{$\begin{array}{l}\mathrm{Ni}^{\mathrm{a}} \\
(\mathrm{wt} . \%)\end{array}$} & \multirow{2}{*}{$\begin{array}{l}D_{\text {reduc. }}{ }^{b} \\
(\%)\end{array}$} & \multirow{2}{*}{$\begin{array}{l}\mathrm{S}_{\mathrm{BET}}^{\mathrm{c}} \\
\left(\mathrm{m}^{2} \mathrm{~g}^{-1}\right)\end{array}$} & \multirow{2}{*}{$\begin{array}{l}\mathrm{S}_{\mathrm{Ni}}^{\mathrm{d}} \\
\left(\mathrm{m}^{2} \mathrm{~g}^{-1}\right)\end{array}$} & \multirow{2}{*}{$\begin{array}{l}\text { Basic. }^{\mathrm{e}} \\
\left(\times 10^{-6} \mathrm{~mol} \mathrm{~g}^{-1}\right)\end{array}$} & \multicolumn{2}{|c|}{$\mathrm{PS}^{\mathrm{f}}(\mathrm{nm})$} \\
\hline & & & & & & $\overline{\mathrm{Ni}}$ & $\overline{\mathrm{MgO}}$ \\
\hline $\mathrm{Ni}-\mathrm{Mg}(1: 9)$ & 14.6 & 52.4 & 193.5 & 2.3 & 362.2 & 7.0 & 7.1 \\
\hline $\mathrm{Ni}-\mathrm{Mg}(2: 8)$ & 28.5 & 40.1 & 141.6 & 4.8 & 285.7 & 8.5 & 6.8 \\
\hline $\mathrm{Ni}-\mathrm{Mg}(3: 7)$ & 38.4 & 36.2 & 106.9 & 6.2 & 257.9 & 9.1 & 6.7 \\
\hline $\mathrm{Ni}-\mathrm{Mg}(4: 6)$ & 47.2 & 27.3 & 99.2 & 5.6 & 229.9 & 10.5 & 6.8 \\
\hline $\mathrm{Ni}-\mathrm{Mg}(5: 5)$ & 56.7 & 18.9 & 79.0 & 3.8 & 175.8 & 10.8 & 6.4 \\
\hline $\mathrm{MgO}$ & - & - & 262.0 & - & 380.8 & - & 9.8 \\
\hline
\end{tabular}

${ }^{\text {a }} \mathrm{Ni}$ loading, determined by ICP analysis.

b Degree of reduction, quantified from $\mathrm{H}_{2}$-TPR data.

c BET surface area, measured by $\mathrm{N}_{2}$-TPD.

d $\mathrm{Ni}$ surface area, characterized with $\mathrm{H}_{2}$ chemisorption.

e Basicity, measured by $\mathrm{CO}_{2}$-TPD.

${ }^{\mathrm{f}}$ Particle size, calculated in XRD characterization from the Scherrer equation.

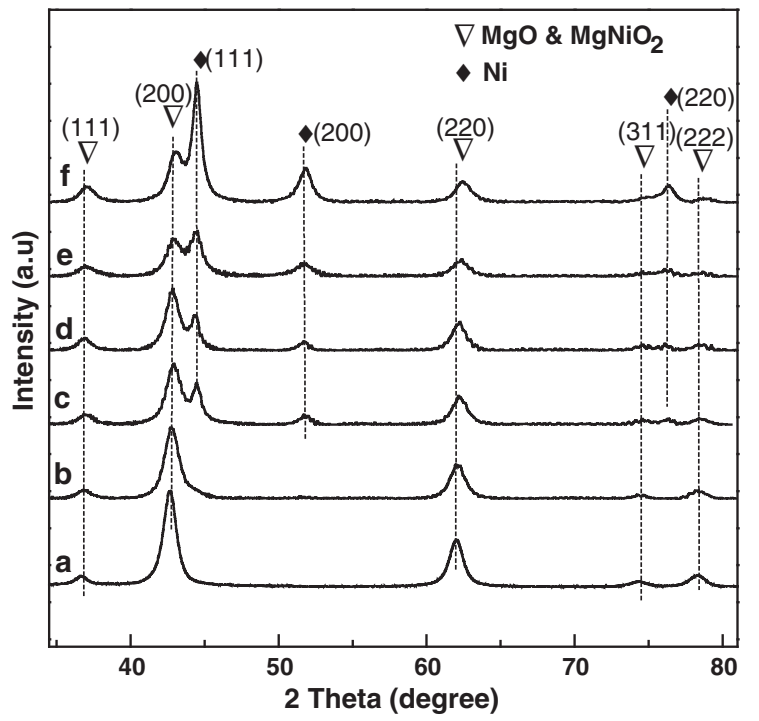

Fig. 1. XRD patterns of $\mathrm{MgO}$ (a), $\mathrm{Ni}-\mathrm{Mg}(1: 9)$ (b), $\mathrm{Ni}-\mathrm{Mg}(2: 8)$ (c), $\mathrm{Ni}-\mathrm{Mg}(3: 7)$ (d), $\mathrm{Ni}-\mathrm{Mg}(4: 6)$ (e) and $\mathrm{Ni}-\mathrm{Mg}(5: 5)$ (f) samples.

lessened from $52.4 \%$ to $18.9 \%$ and the average size of Ni particles was about $10 \mathrm{~nm}$.

\subsection{Hydrogenolysis of sorbitol on Ni-MgO catalysts}

Table 2 presented the results of sorbitol hydrogenolysis over $\mathrm{Ni}-\mathrm{MgO}$ catalysts under relatively mild conditions of $473 \mathrm{~K}$ and $4 \mathrm{MPa}_{2}$, and sorbitol was mostly converted to glycerol and lower glycols mainly containing EG and 1,2-PG. Other compounds like sorbitans, mannitol, acetylacetone and lactic acid were also observed. The total carbon balance ranged from $92.3 \%$ to $100.3 \%$ for all the tests. When the $\mathrm{Ni}-\mathrm{Mg}(1: 9)$ catalyst was used, a $47.4 \%$ sorbitol conversion with a $66.2 \%$ total selectivity of glycols and glycerol was obtained. With Ni content increasing, the sorbitol conversion was improved to the biggest value of $67.8 \%$ over $\mathrm{Ni}-\mathrm{Mg}(3: 7)$ catalyst, and then dropped as the $\mathrm{Ni}$ loading continued to increase. The total selectivity of EG, 1,2-PG and glycerol, also reached the maximum of $80.8 \%$ on $\mathrm{Ni}-\mathrm{Mg}(3: 7)$ catalyst. The activity deterioration for the $\mathrm{Ni}-\mathrm{Mg}(4: 6)$ and $\mathrm{Ni}-\mathrm{Mg}(5: 5)$ catalysts compared with the catalysts with lower Ni-Mg ratios could be ascribed to the decrease of basicity and $\mathrm{Ni}$ surface area which were critical in the $\mathrm{C}-\mathrm{C}$ bond cleavage and the subsequent hydrogenation $[3,6]$.

From the reaction mechanism, the strong basicity of catalyst was conducive to the $\mathrm{C}-\mathrm{C}$ scission in the retro-aldol condensation. Sorbitol and intermediates might also be abundantly adsorbed on the plentiful

Table 2

Hydrogenolysis of sorbitol over Ni-MgO catalysts. $^{\text {a }}$

\begin{tabular}{|c|c|c|c|c|c|c|c|c|}
\hline \multirow[t]{2}{*}{ Enter } & \multirow[t]{2}{*}{ Catalyst } & \multirow{2}{*}{$\frac{\text { Sorbitol }}{\text { Conv. (\%) }}$} & \multicolumn{5}{|c|}{ Product selectivity (\%) } & \multirow{2}{*}{$\begin{array}{l}\mathrm{TC}^{\mathrm{d}} \\
(\%)\end{array}$} \\
\hline & & & EG & $\begin{array}{l}1,2 \\
-P G\end{array}$ & Glycerol & $\begin{array}{l}\text { Gas } \\
\text { products }^{\text {b }}\end{array}$ & Others ${ }^{\mathrm{c}}$ & \\
\hline 1 & $\mathrm{Ni}-\mathrm{Mg}(1: 9)$ & 47.4 & 16.6 & 24.5 & 25.1 & 15.2 & 14.0 & 97.2 \\
\hline 2 & $\mathrm{Ni}-\mathrm{Mg}(2: 8)$ & 61.4 & 18.6 & 30.8 & 23.7 & 12.9 & 11.9 & 98.3 \\
\hline 3 & $\mathrm{Ni}-\mathrm{Mg}(3: 7)$ & 67.8 & 26.0 & 33.7 & 21.1 & 9.7 & 8.1 & 99.6 \\
\hline 4 & Ni-Mg(4:6) & 41.9 & 15.6 & 34.1 & 11.7 & 6.3 & 25.8 & 94.7 \\
\hline 5 & $\mathrm{Ni}-\mathrm{Mg}(5: 5)$ & 33.0 & 10.3 & 28.6 & 10.9 & 10.4 & 29.9 & 93.4 \\
\hline
\end{tabular}

a Reaction conditions: $20 \%$ aqueous sorbitol solution, $50 \mathrm{~mL}$; catalyst amount, $0.5 \mathrm{~g}$; reaction time, $4 \mathrm{~h} ; \mathrm{H}_{2}$ pressure, $4 \mathrm{MPa}$; temperature, $473 \mathrm{~K}$; stirring speed, $600 \mathrm{rpm}$.

b Gas products include $\mathrm{CH}_{4}, \mathrm{CO}_{2}$ and hexane.

c Others include acetone, methanol, ethanol, lactic acid, hydroxyacetone, butanediol, hexanediol, acetonyl acetone, mannitol, erythritol, sorbitans, isosorbide, etc.

d Total carbons, includes total organic carbons and total inorganic carbons. 
alkaline sites to improve the reaction rate [17]. The addition of $\mathrm{MgO}$ or $\mathrm{NaOH}$ promoted the sorbitol conversion, however, the glycol selectivities decreased in spite of the extra alkaline sites introduced by $\mathrm{MgO}$ added (Table S1 in the SI). It could be concluded that the basicity of $\mathrm{Ni}-\mathrm{MgO}$ was strong enough to perfectly facilitate this chemoselective reaction and such alkaline additives were hardly necessary [3]. For the $\mathrm{Ni}-\mathrm{Al}(3: 7)$ catalyst, $\mathrm{NaOH}$ significantly enhanced the sorbitol conversion and the product selectivity, though the resultant conversion was only $48.1 \%$. The result indicated that the acidic carrier $\mathrm{Al}_{2} \mathrm{O}_{3}$ supported metal catalysts should proceed under harsher conditions and with an appropriate amount of basic additives to reduce the byproducts in sorbitol conversion $[5,18]$.

As shown in Table 2, the $\mathrm{Ni}-\mathrm{Mg}(3: 7)$ catalyst with the highest nickel surface area exhibited the best catalytic performance, which suggested that the available active $\mathrm{Ni}$ sites were also essential for this conversion. During the recycling process, $\mathrm{MgO}$ was partly eroded by $\mathrm{H}_{2} \mathrm{O}$, reacted with $\mathrm{CO}_{2}$ and transformed into $\mathrm{MgCO}_{3}$. Therefore, the $\mathrm{Ni}$ nanoparticles aggregated (Fig. S3 in the SI) $[9,19]$. Based on the XRD and $\mathrm{H}_{2}$ chemisorption analysis, the recycled $\mathrm{Ni}-\mathrm{Mg}(3: 7)$ catalyst in the second run possessed $19.4 \mathrm{~nm}$ average-sized Ni clusters with an only $3.5 \mathrm{~m}^{2} / \mathrm{g}$ Ni surface area, over which the sorbitol conversion dropped to $58.7 \%$ along with a $63.5 \%$ total selectivity of EG, 1,2-PG and glycerol (Fig. S2 in the SI). Besides, the products with chelating groups would facilitate leaching and poisoning of Ni catalyst, which also led to the loss of catalytic activity [20]. Over Ni-MgO catalysts, the 1,2-PG selectivity increased and glycerol selectivity decreased with the $\mathrm{Ni} / \mathrm{Mg}$ ratio ranging from $1 / 9$ to $4 / 6$, revealing that the catalysts with higher metal loading also enhanced the glycerol dehydration with $\mathrm{C}-\mathrm{O}$ bond breaking $[3,5,19,21]$. The optimized $\mathrm{Ni} / \mathrm{Mg}$ atomic ratio was $3 / 7$ and the $\mathrm{Ni}-\mathrm{Mg}(3: 7)$ catalyst was chosen to investigate the influences of temperature, $\mathrm{H}_{2}$ pressure and reaction time on the sorbitol hydrogenolysis.

\subsection{The effects of reaction conditions on sorbitol hydrogenolysis}

As revealed in Fig. 2, the sorbitol conversion increased rapidly with temperature increasing from $433 \mathrm{~K}$ to $453 \mathrm{~K}$ and then remained at about $70 \%$, whereas the total selectivity of EG, 1,2-PG and glycerol reached $80.8 \%$ at $473 \mathrm{~K}$ followed by a significant decrease. So, polyols could be considerably converted under a lower temperature, while the further hydrogenation of intermediates into lower glycols would be favorable at the higher appropriate temperature [4]. Product distribution showed that the selectivity towards glycerol was reduced, but the total selectivity of $\mathrm{C} 3$ products including glycerol and 1,2-PG remained almost unchanged with reaction temperature increasing to $473 \mathrm{~K}$. The increasing temperature could accelerate the glycerol hydrogenolysis to 1,2-PG with promoted C-O bond scission [19]. At the temperature higher than $473 \mathrm{~K}$, further degradation of all the glycols was strongly enhanced, resulting in a sharp decline of product selectivity.

Fig. 3 showed that the sorbitol conversion increased significantly with higher $\mathrm{H}_{2}$ pressure, together with a steady growth of glycerol selectivity. In contrast, the selectivity of EG and 1,2-PG reached the maxima of $33.7 \%$ and $26.0 \%$ under $4 \mathrm{MPa}$, and then dropped with the continuously increasing $\mathrm{H}_{2}$ pressure. Thus, the higher $\mathrm{H}_{2}$ pressure could promote the hydrogenation of unsaturated intermediates as well as the further degradation of glycols $[21,22]$. To our knowledge, the optimized $\mathrm{H}_{2}$ pressure of $4 \mathrm{MPa}$ was the lowest, suggesting that the Ni-MgO catalysts were indeed efficient.

As the reaction proceeded, both the sorbitol conversion and the glycerol selectivity gradually increased (Fig. 4). After 8 h, sorbitol was completely converted and the highest glycerol selectivity of $28.1 \%$ was acquired. However, the total selectivity of EG, 1,2-PG and glycerol reached the maximum when the reaction time was extended to $4 \mathrm{~h}$, and subsequently dropped with time. GC analysis indicated that the deep degradation products generally increased over a prolonged period of time, like alcohols, $\mathrm{CO}_{2}, \mathrm{CH}_{4}$, and other alkanes.

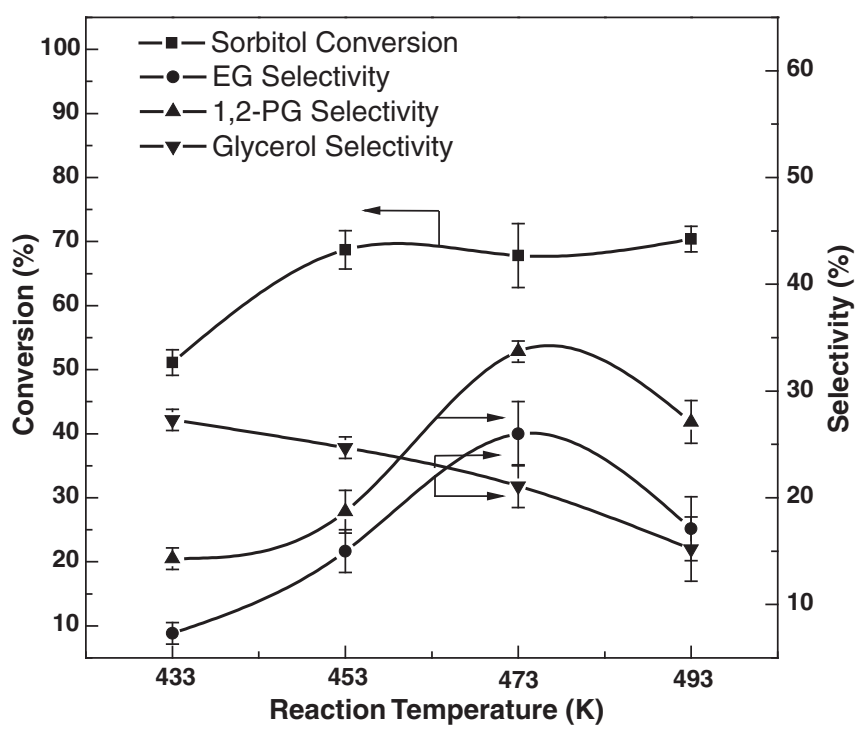

Fig. 2. Effect of reaction temperature on the sorbitol hydrogenolysis over $\mathrm{Ni}-\mathrm{Mg}(3: 7)$ catalyst under $4 \mathrm{MPa} \mathrm{H}_{2}$ for $4 \mathrm{~h}$.

\section{Conclusions}

$\mathrm{Ni}-\mathrm{MgO}$ catalysts were very efficient for sorbitol hydrogenolysis to lower glycols, even under mild conditions and without basic promoters. Characterization results suggested that catalytic performance largely hinged upon the basicity and active metal sites. The poor hydrothermal stability of $\mathrm{Ni}-\mathrm{MgO}$ catalyst would lead to the loss of activity in repeated runs. Under harsh conditions, the deep degradation was accelerated resulting in more byproducts and lower yield of glycols although the sorbitol conversion increased.

\section{Acknowledgements}

This work was supported by the Natural Science Foundation of China (No. 21273260) and the Key Science and Technology Program of Shandong Province (No. 2007GG2QT07006 and No. 2008GG20002038).

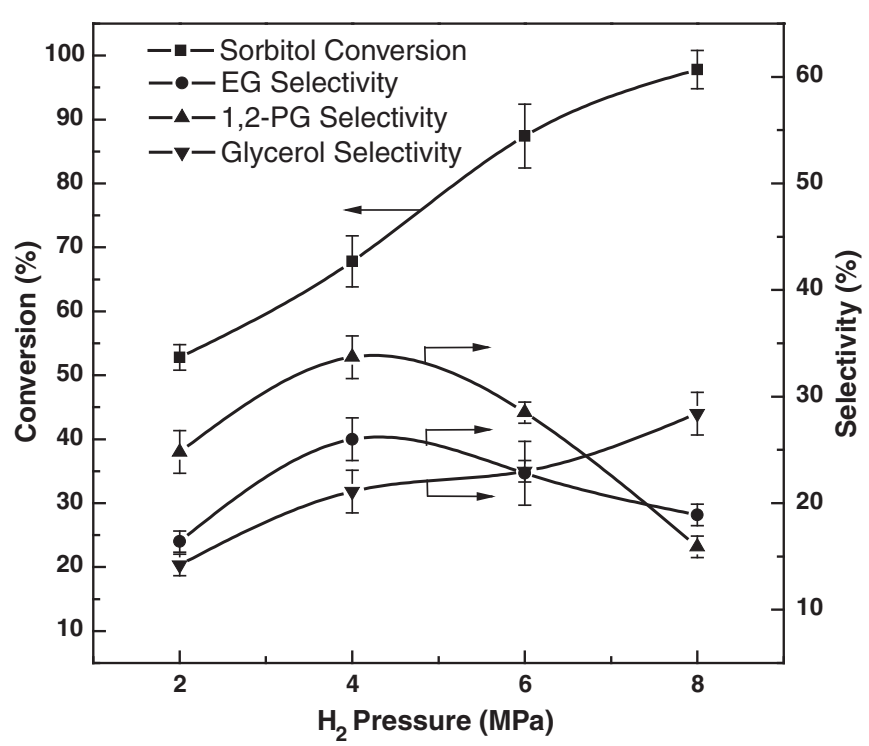

Fig. 3. Effect of $\mathrm{H}_{2}$ pressure on the sorbitol hydrogenolysis over $\mathrm{Ni}-\mathrm{Mg}(3: 7)$ catalyst at $473 \mathrm{~K}$ for $4 \mathrm{~h}$. 


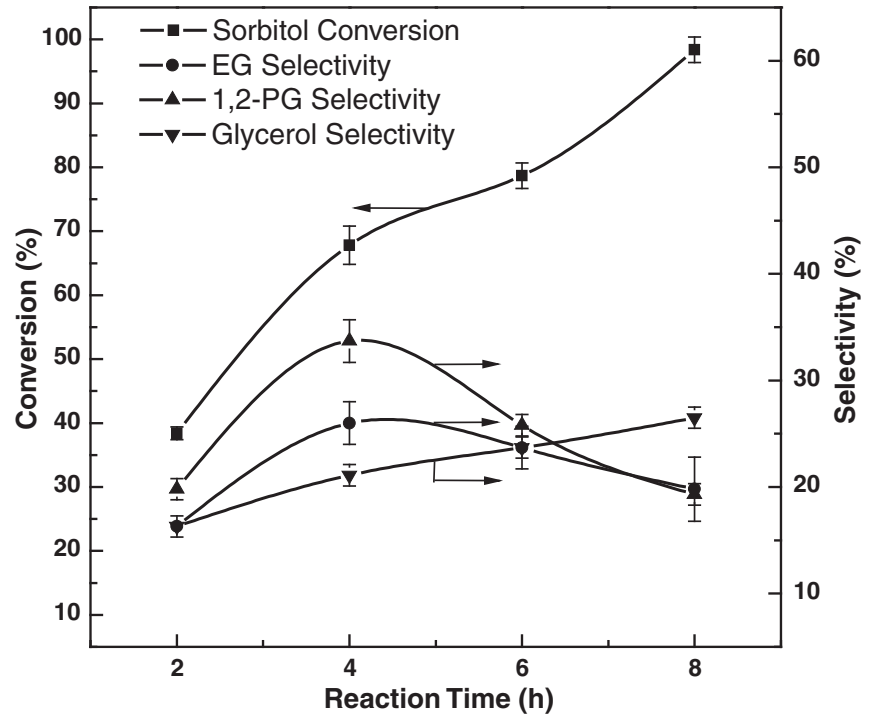

Fig. 4. Effect of reaction time on the sorbitol hydrogenolysis over $\mathrm{Ni}-\mathrm{Mg}(3: 7)$ catalyst under $4 \mathrm{MPa} \mathrm{H}_{2}$ at $473 \mathrm{~K}$.

\section{Appendix A. Supplementary data}

Supplementary data to this article can be found online at http:// dx.doi.org/10.1016/j.catcom.2013.05.012.

\section{References}

[1] J.N. Chheda, G.W. Huber, J.A. Dumesic, Angewandte Chemie, International Edition 46 (2007) 7164.

[2] M.A. Andrews, S.A. Klaeren, Journal of the American Chemical Society 111 (1989) 4131.

[3] L. Zhao, J.H. Zhou, Z.J. Sui, X.G. Zhou, Chemical Engineering Science 65 (2010) 30.

[4] J. Sun, H. Liu, Green Chemistry 13 (2011) 135.

[5] L. Ye, X. Duan, H. Lin, Y. Yuan, Catalysis Today 183 (2012) 65.

[6] K. Wang, M.C. Hawley, T.D. Furney, Industrial \& Engineering Chemistry Research 34 (1995) 3766.

[7] X. Guo, Y. Li, R. Shi, Q. Liu, E. Zhan, W. Shen, Applied Catalysis A: General 371 (2009) 108.

[8] Z. Yuan, P. Wu, J. Gao, X. Lu, Z. Hou, X. Zheng, Catalysis Letters 130 (2009) 261.

[9] Z. Yuan, J. Wang, L. Wang, W. Xie, P. Chen, Z. Hou, X. Zheng, Bioresource Technology 101 (2010) 7099.

[10] U. Saxena, N. Dwivedi, S.R. Vidyarthi, Industrial \& Engineering Chemistry Research 44 (2005) 1466.

[11] L. Zhou, A. Wang, C. Li, M. Zheng, T. Zhang, ChemSusChem 5 (2012) 932.

[12] Y. Echegoyen, I. Suelves, M.J. Lázaro, M.L. Sanjuán, R. Moliner, Applied Catalysis A: General 333 (2007) 229.

[13] X.C. Wang, L.Q. Meng, F. Wu, Y.J. Jiang, L. Wang, X.D. Mu, Green Chemistry 14 (2012) 758.

[14] T. Nakayama, N. Ichikuni, S. Sato, F. Nozaki, Applied Catalysis A: General 158 (1997) 185.

[15] L. Chuanming, C. Donghua, T. Wanjun, P. Yuhua, Journal of Analytical and Applied Pyrolysis 75 (2006) 240.

[16] V. Mohan, C.V. Pramod, M. Suresh, K.H. Prasad Reddy, B.D. Raju, K.S. Rama Rao, Catalysis Communications 18 (2012) 89.

[17] J.X. Li, W.L. Dai, K. Fan, Journal of Physical Chemistry C 112 (2008) 17657.

[18] K.L. Deutsch, D.G. Lahr, B.H. Shanks, Green Chemistry 14 (2012) 1635.

[19] M. Balaraju, K. Jagadeeswaraiah, P.S.S. Prasad, N. Lingaiah, Catalysis Science \& Technology 2 (2012) 1967.

[20] R. Rinaldi, F. Schüth, Energy \& Environment Science 2 (2009) 610

[21] C. Montassier, J.C. Menezo, L.C. Hoang, C. Renaud, J. Barbier, Journal of Molecular Catalysis 70 (1991) 99.

[22] N. Li, G.W. Huber, Journal of Catalysis 270 (2010) 48. 